\title{
Prospective, Randomized Trial Comparing \\ a 3- versus 6-Stitch Purse-String Suture in Stapled Hemorrhoidopexy
}

\author{
Yasuhiro Inoue $^{\text {a }}$ Minako Kobayashi $^{b}$ Shigeyuki Yoshiyama ${ }^{a}$ Junichiro Hiro ${ }^{a}$ \\ Masaki Ohi ${ }^{\mathrm{a}}$ Chikao Miki $^{\mathrm{a}}$ Masato Kusunoki ${ }^{\mathrm{a}, \mathrm{b}}$ \\ a Department of Gastrointestinal and Pediatric Surgery, Division of Reparative Medicine, Institute of Life Sciences, \\ Mie University Graduate School of Medicine, Tsu, and ${ }^{\mathrm{b}}$ Department of Innovative Surgery, Mie University Graduate \\ School of Medicine, Tsu, Japan
}

\section{Key Words}

Stapled hemorrhoidopexy • Purse-string suture •

Mucosal rectal ring

\begin{abstract}
Aim: The purse-string suture is the most important part of the procedure in stapled hemorrhoidopexy affecting resection of an ideal mucosal rectal ring. We designed a prospective, randomized study to evaluate the safety and clinical outcome of a 6-stitch purse-string suture compared with a more simple 3-stitch purse-string suture intended to achieve certain interruption of the hemorrhoidal artery. Methods: Ninety patients were randomly assigned to undergo stapled hemorrhoidopexy with either a 6 -stitch $(n=45)$ or a 3 -stitch $(n=45)$ purse-string suture. Operative data and postoperative complications were compared between the 2 groups. The ring of excised rectal mucosa was examined histologically. Anal physiology was also assessed. Results: Although there were no statistically significant differences in postoperative complication rates, histological analysis of the excised mucosa, or anorectal function between the 2 groups, the 3 -stitch procedure was significantly superior to the 6 stitch procedure in terms of intraoperative hemostasis and operative time, especially in advanced surgery. Conclusion:
\end{abstract}

Once the learning curve has been completed, a 3-stitch purse-string suture in stapled hemorrhoidopexy could be an alternative to the 6 -stitch suture, with effective hemostasis and a shorter operative time.

Copyright $\odot 2007$ S. Karger AG, Basel

\section{Introduction}

The treatment of hemorrhoidal disease using a circular stapler is a simple procedure with low morbidity and less post-treatment pain, but it has the same efficacy compared to the classical hemorrhoidectomy $[1,2]$. This procedure was first introduced by Longo [3], and this technique of stapled hemorrhoidopexy has rapidly gained worldwide acceptance. Although stapled hemorrhoidopexy is not associated with any greater morbidity than conventional techniques, some reports have mentioned the persistence of potential unique complications such as postoperative bleeding, pelvic sepsis, and anal stenosis at follow-up [4-7].

Longo's procedure reduces hemorrhoid prolapse using a circular stapler to transversely resect a mucosal-submucosal rectal ring in order to restore the correct anatomical relationships of the anal canal structures. The first step is

\section{KARGER}

Fax +4161306 1234

E-Mail karger@karger.ch

www.karger.com
(C) 2007 S. Karger AG, Basel

0253-4886/07/0245-0382\$23.50/0

Accessible online at:

www.karger.com/dsu
Masato Kusunoki, Department of Gastrointestinal and Pediatric Surgery

Division of Reparative Medicine, Institute of Life Sciences

Mie University Graduate School of Medicine, Edobashi 2-174

Tsu, Mie 514-8507 (Japan), Tel. +81 59232 1111, ext. 5645, Fax +81 592326968

E-Mail kusunoki@clin.medic.mie-u.ac.jp 
Fig. 1. a Three-stitch purse-string suture. The first stitch was started just before the 3 o'clock position. The second and third stitches were placed where they enabled us to scoop up the hemorrhoidal artery branches at 7 and 11 o'clock. $=$ Hemorrhoidal artery at 3, 7 and 11 o'clock. b Sixstitch purse-string suture. The pursestring suture was started just before the 3 o'clock position. A total of 6 stitches were placed with the same suture, at the same distance from the dentate line.

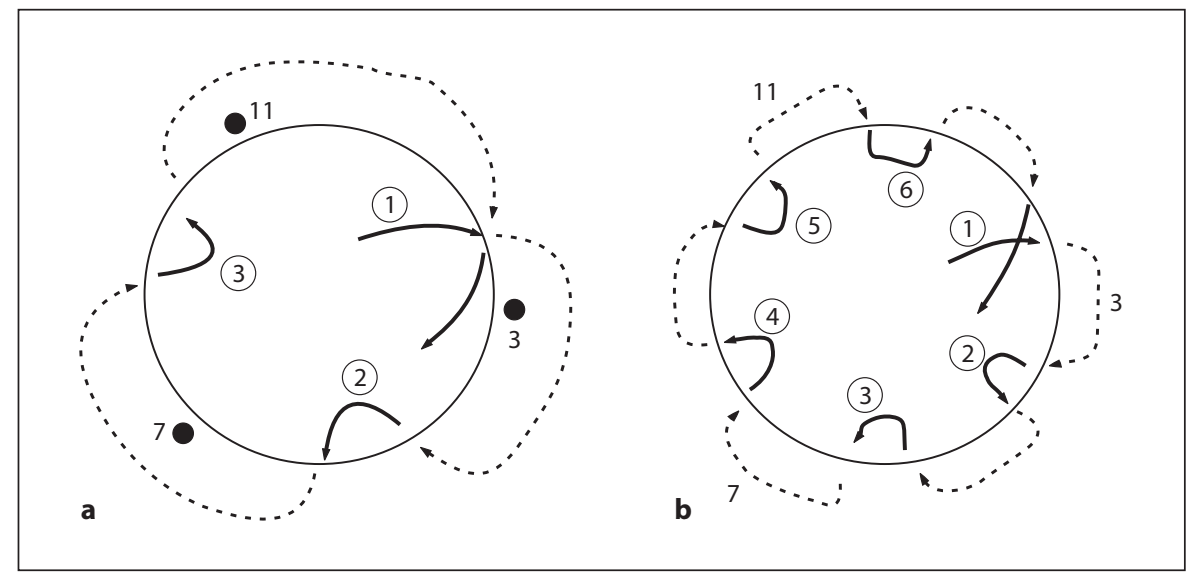

to place the purse-string suture 3-4 $\mathrm{cm}$ above the dentate line using a circular anal dilator and the fenestrated anoscope of the special Procedure for Prolapsed Hemorrhoids (PPH) kit (Ethicon Endosurgery Inc., Cincinnati, Ohio, USA). In placing this purse-string suture, particular care must be given to positioning the stitches at the same level on the posterolateral side to ensure excision of the entire circumference of the mucosal rectal ring, and therefore reduce the risk of some complications. When Longo originally described this technique for the treatment of hemorrhoidal disease, no information was given about the number of stitches suitable for the purse-string suture. In 2002, we communicated personally with Dr. Longo, who advised us that he used about 6 stitches for his purse-string sutures. In Japan, 6-8 stitches have been empirically accepted as effective to tie the entire circumference of the rectal mucosa around the stapler shaft. When we visited Singapore General Hospital in 2002 as a part of our study, they were using a simpler 3-stitch suture. We therefore designed a prospective, randomized study to evaluate the safety and clinical and physiological outcome of using 6 stitches compared with the simpler 3 stitches for the purse-string suture in stapled hemorrhoidopexy.

\section{Patients and Methods}

The study was conducted at the Department of Gastrointestinal and Pediatric Surgery, Division of Reparative Medicine, Institute of Life Sciences, Mie University Graduate School of Medicine, Japan, from September 2002 to November 2006. Local ethics committee approval was obtained. Appropriate informed written consent was obtained from patients admitted for symptomatic hemorrhoids. All patients with grade III and IV hemorrhoids were included in the study. Patients with an acute hemorrhoidal episode with thrombosis or with concomitant anal pathology (fistula and/or fissure) were excluded. Randomization was performed at the time of anesthesia using sealed envelopes. In this study we enrolled 90 consecutive patients who all underwent stapled hemorrhoidopexy. Patients were assigned randomly to one of two groups: 3 -stitch purse-string suture (Singapore $(S)$ procedure, $n=45$ ) or 6 -stitch purse-string suture (Longo (L) procedure, $\mathrm{n}=45$ ). To eliminate bias based on surgeon, all operations were performed by 2 colorectal surgeons who had experience with more than 100 Milligan-Morgan hemorrhoidectomies. The operator was a junior surgeon (M.K.), and the assistant a senior surgeon (Y.I.). As the operator was a junior surgeon, we also evaluated the learning curve of each procedure.

\section{Techniques}

All operations were performed without bowel preparation. Prophylactic antibiotics were not routinely given. Operations were performed under general anesthesia in the lithotomic position. Local infiltration of adrenaline was not used. Stapled hemorrhoidopexy was performed using the Ethicon $\mathrm{PPH} 33^{\circledR}$ circular stapler (Ethicon Endo-Surgery). An instrument kit PPH-01 (closed staple height range 1-2.5 mm) was used from September 2001 to April 2004, and the new PPH-03 (closed staple height range $0.75-1.5 \mathrm{~mm}$ ) was used from May 2004. To ensure that the purse-string suture was placed an appropriate distance from the dentate line, 6 traction stitches were placed quite close to the anal verge before introducing a transparent anal dilator. The dentate line was clearly visible through the anal dilator and could therefore easily be protected. The Purse String Anoscope ${ }^{\circledR}$ (Ethicon Endosurgery) was then introduced through the CAD $33^{\circledR}$, and a circumferential purse-string suture of 2-0 polypropylene was placed $4 \mathrm{~cm}$ proximal to the dentate line. A $30-\mathrm{mm}$ curved, roundbodied needle was used for the $\mathrm{S}$ procedure. When the hemorrhoidal artery at the 3 o'clock position was palpated, the first stitch was started at just before the artery to ensure interruption of the artery. The second and third stitches were placed so as to enable us to scoop up the hemorrhoidal arteries at the 7 and 11 o'clock positions. If we failed to palpate the artery, the first stitch was routinely started just before the 3 o'clock position (fig. 1a). A 26$\mathrm{mm}$ curved, round-bodied needle was used for the $\mathrm{L}$ procedure. 
The purse-string suture with 6 stitches was started just before the 3 o'clock position (fig. 1b). The circular stapler was opened to its maximum position and positioned proximal to the purse-string. The purse-string was then tightened. In women, the posterior vaginal wall was checked to prevent entrapment. The stapler was then fired and held in position for $30 \mathrm{~s}$ to ensure hemostasis. The stapled line was inspected for any bleeding and, if present, hemostatic sutures were placed with 3-0 Vicryl. Our policy for suture requirement was not only spurting but also any oozing and nine hemostatic sutures were taken as a basis in this study, since the average number of sutures for hemostasis in our previous consecutive series $(n=20)$ was $8.7 \pm 3.5$. In all cases, Spongostan ${ }^{\circledR}$ was placed in the anal canal to prevent postoperative bleeding. All the mucosal rectal rings obtained were sent for histopathological examination to assess the area of excised mucosa and to check for any circular muscle included in the specimen.

\section{Measured Outcomes}

Clinical Assessment

Operative data and postoperative complications were recorded. Postoperative hemorrhage was defined as bleeding requiring surgical intervention or readmission to hospital after discharge.

\section{Assessment of the Mucosal Rectal Ring}

After surgery, the ring of excised anorectal mucosa was cut open and secured to a piece of cardboard. The length and maximum and minimum width of the specimen were measured. The total area of excised mucosa was calculated by multiplying length by mean width. Muscle presence in the specimen was confirmed macroscopically and photographed. Photographs were stored on a personal computer. The presence of smooth muscle was also confirmed histopathologically. A quantitative histological measurement was made of the muscle contained in each specimen to determine the proportion of muscle to background mucosa, using the imaging analyzing system (Win Roof Version 3.6; Mitani Corp., Japan) as described previously in an irradiated rectal cancer study [8]. The amount of smooth muscle excised is expressed quantitatively as a percentage of the total tissue removed (fig. 2).

\section{Anal Physiological Assessment}

All patients underwent continence evaluation using anorectal manometry before surgery, as previously described [9]. This was repeated 1 month after the operation to assess postoperative function.

\section{Statistical Analysis}

Through power calculations with a two-sided t test, we estimated that approximately 45 patients were necessary in each arm to detect a $30 \%$ difference in intraoperative hemostasis with an $80 \%$ power and a $5 \%$ significance level. The results are presented as mean $\pm \mathrm{SD}$, and were subjected to a nonparametric MannWhitney U test. A paired Student's t test was also used to analyze intra-group differences. Correlations were analyzed using the Pearson coefficient analysis. Contingency tables were analyzed using Fisher's exact probability test or $\chi^{2}$ test with Yates' correction. A p value of 0.05 was considered significant.

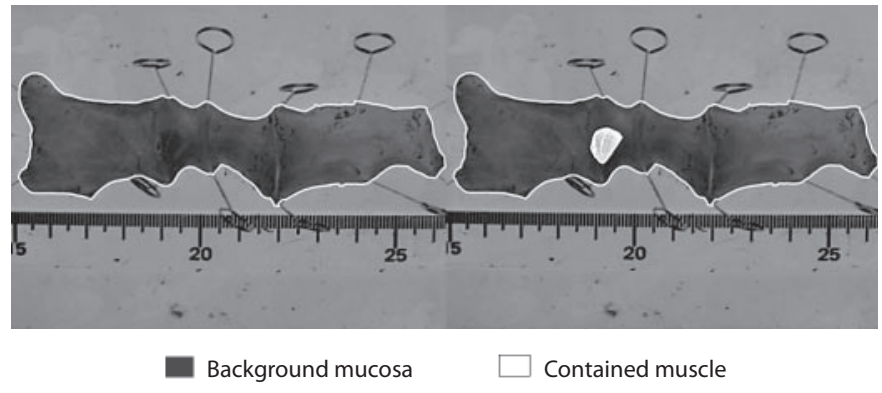

Contained muscle rate $(\%)=$ contained muscle/background mucosa $\times 100$

Fig. 2. A quantitative histological measurement was made of the muscle contained in each specimen to determine the proportion of muscle to background mucosa, using the imaging analyzing system. The amount of smooth muscle excised was expressed quantitatively as a percentage of the total tissue removed.

Table 1. Demographic and clinical features

\begin{tabular}{llll}
\hline & \multicolumn{2}{c}{ Purse-string suture $(\mathrm{n}=45)$} & $\mathrm{p}$ value \\
\cline { 2 - 3 } & 3-stitch & 6 -stitch & \\
\hline Age, years & $54.7 \pm 16.3$ & $60.8 \pm 16.0$ & n.s. \\
$\begin{array}{l}\text { Gender, m/f } \\
\text { Chief complaint }\end{array}$ & $29 / 16$ & $26 / 19$ & n.s. \\
$\quad$ Bleeding & 31 & 27 & \\
$\quad$ Prolapse & 11 & 8 & n.s. \\
$\quad$ Pain & 2 & 7 & n.s. \\
$\quad$ Itching & 1 & 3 & n.s. \\
Grading & & & n.s. \\
$\quad$ Grade III & 36 & 30 & n.s. \\
$\quad$ Grade IV & 9 & 15 & n.s. \\
\hline
\end{tabular}

\section{Results}

Demographic and clinical features are listed in table 1. The groups were well matched for age, gender, type of symptom, and degree of hemorrhoids, with no significant differences. A total of 90 patients underwent stapled hemorrhoidopexy. Forty-five patients were randomly assigned to the L procedure group and 45 to the $S$ procedure group. No significant events occurred in any of the operations.

The intraoperative and postoperative parameters evaluated in the 2 groups are presented in table 2 . Surgery was significantly shorter for the $\mathrm{S}$ procedure than for the $\mathrm{L}$ procedure $(24.4 \pm 10.2$ vs. $34.7 \pm 14.6 \mathrm{~min}, \mathrm{p}<0.0001)$. All patients required at least one hemostatic suture after stapling. The number of hemostatic sutures required to 
Table 2. Valuables related to surgery

\begin{tabular}{|c|c|c|c|}
\hline & \multicolumn{2}{|c|}{ purse-string suture $(\mathrm{n}=45)$} & \multirow[t]{2}{*}{$\mathrm{p}$ value } \\
\hline & 3-stitch & 6-stitch & \\
\hline Operative time, min & $24.4 \pm 10.2$ & $34.7 \pm 14.6$ & $<0.0001$ \\
\hline Hemostatic suture & $6.4 \pm 2.0$ & $9.4 \pm 5.1$ & 0.0104 \\
\hline Staple suture distance, $\mathrm{cm}$ & $2.6 \pm 0.6$ & $2.4 \pm 0.7$ & n.s. \\
\hline \multicolumn{4}{|l|}{ Complications } \\
\hline Postoperative bleeding & 0 & 1 & n.s. \\
\hline Urinary retention & 1 & 1 & n.s. \\
\hline Anal fissure & 4 & 3 & n.s. \\
\hline Hematoma & 1 & 1 & n.s. \\
\hline Pain (analgesics required) & 3 & 2 & n.s. \\
\hline Recurrent prolapse & 0 & 2 & n.s. \\
\hline
\end{tabular}

stop anastomotic bleeding was significantly less for the $S$ procedure than for the $\mathrm{L}$ procedure $(6.4 \pm 2.0 \mathrm{vs} .9 .4 \pm$ $5.1, \mathrm{p}=0.0104)$. No significant difference was found in the mean distance between the line of staples and the dentate line $(2.6 \pm 0.6$ vs. $2.4 \pm 0.7 \mathrm{~cm})$.

\section{Complications}

The total complication rate after surgery in this study was $21.1 \%$ (19/90). Other than postoperative bleeding, there were no severe complications (such as pelvic sepsis, stenosis or rectovaginal fistula). One patient (1.1\%) who underwent the $\mathrm{L}$ procedure had severe bleeding per rectum during the first $24 \mathrm{~h}$ after surgery. This patient required emergency return to the operating theater to control the bleeding under anesthesia. Postoperative pain was evaluated by analgesic requirements. Five patients (5.6\%) had persistent pain requiring analgesics. There was no statistical difference in the use of analgesics between the 2 groups. Urinary retention (2.2\%), anal fissure (7.8\%), and submucosal hematoma (2.2\%) were also observed in our study; however, the incidence of these complications was comparable between the 2 groups. Two patients in the $\mathrm{L}$ group had recurrent hemorrhoidal prolapse and 1 of them underwent Milligan-Morgan hemorrhoidectomy 6 months after stapled hemorrhoidopexy.

\section{Assessment of the Mucosal Rectal Ring}

No excised mucosal rectal rings were torn. However, there were some with disproportionate width. The mean width was $29.4 \pm 6.4 \mathrm{~mm}$ and mean length was $119.0 \pm$ $13.9 \mathrm{~mm}$. The total area of excised mucosa was calculated by multiplying length by mean width. No significant difference was found in the total area of excised mucosa between the 2 groups $\left(33.3 \pm 7.5\right.$ vs. $\left.36.6 \pm 7.9 \mathrm{~cm}^{2}\right)$. A quantitative histological measurement was made of the muscle contained in each specimen to determine the proportion of muscle to background mucosa, using the imaging analyzing system. The mean amount of smooth muscle excised was $7.5 \pm 3.9 \%$ (range 1.0-17.0\%), expressed quantitatively as a percentage of the total tissue removed. There was no significant difference in the muscle contained in the specimens between the two procedures $(7.7 \pm 3.9$ vs. $7.2 \pm 4.0 \%)$. No significant correlations were found between these histological measurements and postoperative complications.

\section{Anorectal Function}

None of our patients had any complaint of continence disorders at follow-up. There were no statistically significant differences between pre- and postoperative manometric values in either procedure. In the $L$ group, mean resting pressure $(\mathrm{MRP})$ was $36.3 \pm 2.1 \mathrm{~mm} \mathrm{Hg}$ before the operation and $35.0 \pm 7.0 \mathrm{~mm} \mathrm{Hg} 1$ month after the operation. The mean maximal squeeze pressure (MMSP) was $155.0 \pm 58.9 \mathrm{~mm} \mathrm{Hg}$ before the operation and 195.0 $\pm 57.6 \mathrm{~mm} \mathrm{Hg} 1$ month after the operation. In the S group, the MRP was $47.4 \pm 16.9 \mathrm{~mm} \mathrm{Hg}$ before the operation and $47.4 \pm 13.4 \mathrm{~mm} \mathrm{Hg} 1$ month after the operation, and the MMSP was $132.8 \pm 56.9 \mathrm{~mm} \mathrm{Hg}$ before the operation and $126.3 \pm 35.7 \mathrm{~mm} \mathrm{Hg} 1$ month after the operation. The differences in MRP and MMSP were not correlated with the percentage of smooth muscle removed in this study.

\section{Learning Curve}

We evaluated the learning curve of each procedure every 5 consecutive cases. For the $S$ procedure, we observed a learning curve with regard to operative time. After 20 
Fig. 3. a Compared to the $\mathrm{L}$ procedure, there was a significant improvement in operative time for the $\mathrm{S}$ procedure after experience with 20 patients. b There was an improvement in intraoperative hemostasis for the $S$ procedure after experience with 20 patients.

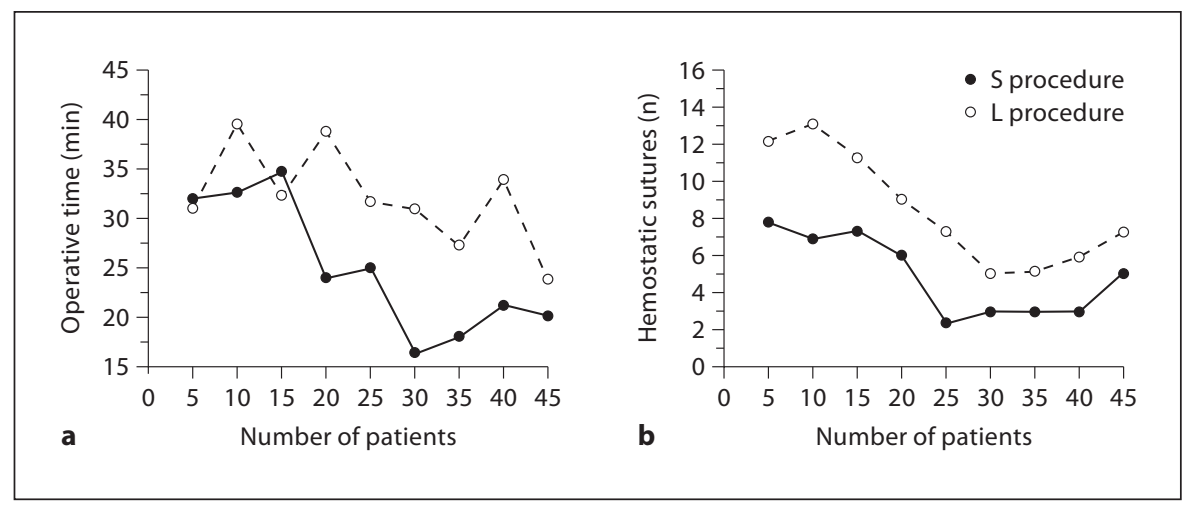

patients there was a significant improvement in operative time over that of the L procedure (fig. 3a). There was also an improvement in intraoperative hemostasis for the $S$ procedure after 20 patients (fig. $3 \mathrm{~b}$ ).

\section{Discussion}

Stapled hemorrhoidopexy offers a novel approach to the treatment of hemorrhoids. The procedure involves interruption of the terminal branches of the superior hemorrhoidal arteries, excision of part of the prolapsed mucosa, raising the mucosa and fixing it back in the anal canal above the high-pressure zone, thus correcting the prolapse and improving the venous return. In this procedure, crucial emphasis has been placed on the depth of the purse-string suture to avoid excess muscle incorporation, but to obtain a sufficient circumference of the mucosal rectal ring. Although several studies have reported the superiority of the stapled hemorrhoidopexy [10-13], few reports describe the precise technique for placement of the purse-string suture to obtain excision of the ideal mucosal rectal ring. There are two starting points for the purse-string suture described in the literature: the anterior rectal wall $[1,14,15]$ and the 3 o'clock position $[16$, 17]. However, there seem to be no particular reasons given for using one or the other. There are also no descriptions of the number of stitches suitable for a purse-string suture.

In this study, we have attempted to clarify and evaluate an effective method to tie the entire circumference of the rectal mucosa around the stapler shaft. We paid particular attention to the original concept of stapled hemorrhoidopexy interrupting the end branches of the upper hemorrhoidal artery. The distribution of the main trunk of the superior rectal artery determines the position of hemorrhoidal piles around the anal circumference. These vessels are generally at the 3,7 , and 11 o'clock positions as viewed in the anatomical lithotomy position [18]. To be certain of interrupting the hemorrhoidal artery, we first palpated the hemorrhoidal artery at 3 o'clock, and placed the first stitch starting just before the artery. In the $\mathrm{S}$ procedure, the second and third stitches were placed where they enabled us to scoop up the hemorrhoidal arteries at 7 and 11 o'clock (fig. 1a).

The total complication rate after stapled hemorrhoidopexy in this study was $21.1 \%$, consistent with previous reports $[19,20]$. In their review of stapled hemorrhoidopexy, Nisar et al. [21] found that immediate postoperative hemorrhage, one of the most frequent complications, was reported in several trials [22-24] and occurred in $9.6 \%$ of all stapled procedures. However, we experienced only 1 patient $(1.1 \%)$ with postoperative hemorrhage. This might be the result of placing our purse-string suture with attention paid to the distribution pattern of the hemorrhoidal arteries. The $S$ procedure was significantly superior to the L procedure in terms of intraoperative hemostasis, and consequently operative time.

Our results do not show a statistically significant difference in postoperative complications between the two procedures. Assessment of the ring of excised anorectal mucosa did not show a significant histological difference, including in the muscle contained, between the 2 groups. Anal physiological assessments did not reveal any statistically significant differences between pre- and postoperative manometric values in either group.

To eliminate bias based on surgeon, one junior surgeon performed all the operations in our study. We evaluated the learning curve of each procedure. The results show that there is not much difference between the $S$ and $\mathrm{L}$ procedures initially, however, the $\mathrm{S}$ procedure shows benefits which are dependent on operator skills. Experi- 
ence with 20 patients enabled us to use the $S$ procedure safely and effectively with good intraoperative hemostasis and a short operative time. The L procedure pursestring suture may be easier to place if huge piles obscure the operative field of vision, though we did not find significant differences in the operative time between grade III and IV hemorrhoids. In other words, the L procedure should be used by an inexperienced surgeon in some hemorrhoidal conditions, and the $S$ procedure should be used by an experienced surgeon.

\section{Conclusion}

Our results show that the $S$ procedure is as simple, safe and effective a method for the treatment of hemorrhoids as the $\mathrm{L}$ procedure. Once the learning curve is completed, the $S$ procedure could be used as an alternative to the $\mathrm{L}$ procedure, with effective hemostasis and a shorter operative time. The favorable data from this trial have moved us toward the proper use of the purse-string suture in stapled hemorrhoidopexy, depending on operator skills or hemorrhoidal conditions.

\section{References}

1 Senagore AJ, Singer M, Abcarian H, Fleshman J, Corman M, Wexner S, Nivatvongs S; Procedure for Prolapse and Hemmorrhoids $(\mathrm{PPH})$ Multicenter Study Group: A prospective, randomized, controlled multicenter trial comparing stapled hemorrhoidopexy and Ferguson hemorrhoidectomy: perioperative and one-year results. Dis Colon Rectum 2004;47:1824-1836.

-2 Gravie JF, Lehur PA, Huten N, Papillon M, Fantoli M, Descottes B, Pessaux P, Arnaud JP: Stapled hemorrhoidopexy versus Milligan-morgan hemorrhoidectomy: a prospective, randomized, multicenter trial with 2year postoperative follow up. Ann Surg 2005; 242:29-35.

3 Longo A: Treatment of hemorrhoidal disease by reduction of mucosa and hemorrhoidal prolapse with circular suturing device: a new procedure. Proc 6th World Congr Endoscopic Surgery, Rome 1998, pp 777-790.

4 Molloy RG, Kingsmore D: Life threatening pelvic sepsis after stapled haemorrhoidectomy. Lancet 2000;355:810.

5 Maw A, Eu KW, Seow-Choen F: Retroperitoneal sepsis complicating stapled hemorrhoidectomy: report of a case and review of the literature. Dis Colon Rectum 2002;45: 826-828.

-6 Ripetti V, Caricato M, Arullani A: Rectal perforation, retropneumoperitoneum, and pneumomediastinum after stapling procedure for prolapsed hemorrhoids: report of a case and subsequent considerations. Dis Colon Rectum 2002;45:268-270.

7 MacRae HM, McLeod RS: Handsewn vs. stapled anastomoses in colon and rectal surgery: a meta-analysis. Dis Colon Rectum $1998 ; 41: 180-189$
8 Kusunoki M, Yanagi H, Kamikonya N, et al: Significant effect of preoperative brachytherapy on survival rate after resection of rectal carcinoma. Int J Oncol 1996;9:645651.

-9 Kusunoki M, Shoji Y, Yanagi H, Hatada T, Fujita S, Sakanoue Y, Yamamura T, Utsunomiya J: Function after anoabdominal rectal resection and colonic J pouch-anal anastomosis. Br J Surg 1991;78:1434-1438.

10 Brown SR, Ballan K, Ho E, Ho Fams YH, Seow-Choen F: Stapled mucosectomy for acute thrombosed circumferentially prolapsed piles: a prospective randomized comparison with conventional haemorrhoidectomy. Colorectal Dis 2001;3:175-178.

11 Rowsell M, Bello M, Hemingway DM: Circumferential mucosectomy (stapled haemorrhoidectomy) versus conventional haemorrhoidectomy: randomised controlled trial. Lancet 2000;355:779-781.

12 Khalil KH, O’Bichere A, Sellu D: Randomized clinical trial of sutured versus stapled closed haemorrhoidectomy. Br J Surg 2000; 87:1352-1355.

13 Ng KH, Ho KS, Ooi BS, Tang CL, Eu KW: Experience of 3711 stapled haemorrhoidectomy operations. Br J Surg 2006;93:226230.

14 Mascagni D, Zeri KP, Di Matteo FM, Peparini N, Maturo A, Berni A: Stapled hemorrhoidectomy: surgical notes and results. Hepatogastroenterology 2003;50:1878-1882.

$\checkmark 15$ Arnaud JP, Pessaux P, Huten N, De Manzini N, Tuech JJ, Laurent B, Simone M: Treatment of hemorrhoids with circular stapler, a new alternative to conventional methods: a prospective study of 140 patients. J Am Coll Surg 2001;193:161-165.

-16 Lloyd D, Ho KS, Seow-Choen F: Modified Longo's hemorrhoidectomy. Dis Colon Rectum 2002;45:416-417.
17 Bikhchandani J, Agarwal PN, Kant R, Malik VK: Randomized controlled trial to compare the early and mid-term results of stapled versus open hemorrhoidectomy. Am J Surg 2005; 189:56-60.

18 Miles WE: Observation upon internal piles. Surg Gynecol Obstet 1919;29:497-506.

19 Ganio E, Altomare DF, Gabrielli F, Milito G, Canuti S: Prospective randomized multicentre trial comparing stapled with open haemorrhoidectomy. Br J Surg 2001;88:669-674.

20 Boccasanta P, Capretti PG, Venturi M, Cioffi U, De Simone M, Salamina G, Contessini-Avesani E, Peracchia A: Randomised controlled trial between stapled circumferential mucosectomy and conventional circular hemorrhoidectomy in advanced hemorrhoids with external mucosal prolapse. Am J Surg 2001;182:64-68.

-21 Nisar PJ, Acheson AG, Neal KR, Scholefield $\mathrm{JH}$ : Stapled hemorrhoidopexy compared with conventional hemorrhoidectomy: systematic review of randomized, controlled trials. Dis Colon Rectum 2004;47:18371845.

22 Hetzer FH, Demartines N, Handschin AE, Clavien PA: Stapled vs. excision hemorrhoidectomy: long-term results of a prospective randomized trial. Arch Surg 2002;137:337340 .

23 Wilson MS, Pope V, Doran HE, Fearn SJ, Brough WA: Objective comparison of stapled anopexy and open hemorrhoidectomy: a randomized, controlled trial. Dis Colon Rectum 2002;45:1437-1444.

24 Cheetham MJ, Cohen CR, Kamm MA, Phillips RK: A randomized, controlled trial of diathermy hemorrhoidectomy vs. stapled hemorrhoidectomy in an intended day-care setting with longer-term follow-up. Dis Colon Rectum 2003;46:491-497. 